\title{
Experimental Evaluation of the Effect of Thread Angle on the Fatigue Life of Bolts
}

\author{
Er. Shuhaib Mushtaq*, Dr. Nazir Ahmad Sheikh** \\ *Research Scholar, Department of Mechanical Engineering, National Institute of Technology, Srinagar, India \\ ** Assistant Professor, Department of Mechanical Engineering, National Institute of Technology, Srinagar, \\ India
}

\begin{abstract}
The present work is concerned with fatigue strength, obtained by plotting the $S$-N Curves for determining the fatigue life of various thread geometries of bolts under cyclic loading. The stress equations obtained from Majzoobi are being used for calculations of core stress " $\sigma_{\text {core }}$ " produced due to cyclic loading, which is being carried usually by the first thread of the bolt. The higher stress concentration occurs in the root of first threads. The experimental work has been carried out for five different thread profiles of varying flank angles, having six samples of each profile. The fatigue testing on each profile has been performed under cyclic loading, in order to obtain the number of cycles to failure of a particular specimen. The results obtained experimentally have been compared with the work of Gane. Finally the work is used to obtain the failure life of bolts, which means which thread profile has higher fatigue life or simply higher strength to failure. As strength is of direct use to the designer regarding the safety of structures.
\end{abstract}

Keywords: Fatigue, ISO Bolts, Thread, Pitch, Diameter

\section{Introduction}

Bolts and screws play an important role in the performance of machinery. The majority of these fasteners are subjected to fluctuating loads, leading to the well known phenomenon of fatigue which is responsible for most of the premature failure in bolts. The word fatigue has been derived from fatigare which means 'to tire' is the widely accepted terminology in engineering and scientific vocabulary for the failure of materials under cycling loading. It has been estimated that fatigue contributes to approximately $90 \%$ of all mechanical service failures. The term fatigue has been defined as changes in properties which can occur in metallic materials by the repeated application of stress and strain. When a metal is subjected to alternating loads after many reversals the whole character of metal may change. Fatigue cracks as presented by Higgins [1] almost always initiate at free surfaces, usually external surfaces but also internal surfaces if the metal contains defects such as voids and cracked second-phase particles. Common external surface defects include geometric notches and surface roughness. Fatigue crack nucleation and growth occurs in the following stages. Stage I. Crack initiation usually starts at a notch or other surface discontinuity. Even in the absence of a surface defect, crack initiation will eventually occur due to the formation of persistent slip bands (PSBs), so called because traces of the bands persist even when the surface damage is polished away. Slip bands are a result of the systematic build up of fine slip movements in the order of only $1 \mathrm{~nm}$. However, the plastic strain within the PSB can be as much as 100 times greater than that in the surrounding material. The back-and-forth movement of the slip bands leads to the formation of intrusions and extrusions at the surface, eventually leading to the formation of a crack.The presence of geometrical discontinuities (holes, changes of section) causes stress concentrations which increase the stresses locally and influence resistance to fatigue. Stress concentrations occur in bolts at the thread roots, thread run-out and at the radius under the head. Fatigue failures in bolts in fluctuating tension commonly occur at this last location or in the first thread under the nut. The design of the joint is very important; the fatigue strength finally depends on the real path of the loads through the connection, and the fluctuation in stresses of the fatigue sensitive regions. The thread in a bolt acts as a notch and therefore a high stress concentration is caused at the root of the thread. At two locations of the thread the stress concentration can be even higher, i.e. at the runout of the thread and where the thread of the nut first engages the thread of the bolt. In addition, the head-shank transition is also a stress concentration. There are, therefore, basically three locations in a bolt with nut axially loaded, where a fatigue crack can initiate in a bolt with nut axially loaded. These locations are: head-shank transition, run out of thread, thread at nut. In standard bolts the radius at the bolt-head shank transition is large enough to prevent fatigue cracks at this point. Normally, if fatigue cracks occur, they will be located at the first engagement of the threads of the bolt and nut. This is due to the load transfer from nut to bolt.

It is evident that the fatigue strength of a bolt is largely influenced by the stress concentration at the root of first thread of the bolt which carries most of the load. The distribution of the load between the engaging threads has 
been investigated by many researchers such as Maduschka[13] and Birger[14] and has been fully reviewed by Kenny and Patterson $[15,16]$. One theory for the load distribution is provided by Sopwith[17] modified later by Stoeckly and Macke [18]. The load distribution is given by:

$$
w(x)=w_{m} \frac{e^{u[1-x]}}{\sinh (v)}(v \cosh (v x)-u \sinh (v x))
$$

Where $w(x)$ is the axial load per unit length of contact at the normalized position $x$ along the thread, $x$ is the ratio between the distance from the free face of the nutand nut length, $w_{m}$ is the mean value of $w$ over the contact length $\left(\cong \pi d_{p} L / p\right)$ and $\mathrm{u}$ and $\mathrm{v}$ are constants which can be found in Ref. [18].

Simple considerations of stress concentration by Gane [19] predict that the three most important geometric variables affecting the strength of the threaded connection are thread depth; root radius and flank angle $\left(60^{\circ}\right.$ in most standard threads). Thread depth is directly related to thread pitch (distance between adjacent thread peaks); a deep thread must of necessity be a coarse thread for a given flank angle. For a $60^{\circ}$ thread, $\mathrm{h}=$ $\sqrt{3} p$, where $\mathrm{h}$ is the thread depth and $\mathrm{p}$ is the thread pitch, as the radius increases the length of flank contact between the bolt and nut is reduced. This length of flank engagement transmits the load from the nut to the bolt. Also, a decrease in flank angle will decrease the maximum root radius that may be used. Within these constraints an experimental plan was drawn up using flank angle, thread pitch and root radius as variables.

The highest stress concentration occurs in the root of the first thread engaged between bolt and nut, with a large proportion of the load carried by the first thread. This contact load produces a bending stress in the root of the threads along with an axial load that produces tension in the bolt core. Both the bending and axial stresses contribute to the stress concentration. The maximum bending and axial stress, $\sigma_{x}$ and $\sigma_{y}$, respectively, occurs at the root of thread. The axial stress, $\sigma_{y}$ is given by:

$$
\sigma_{y}=k_{t} \frac{P}{A_{\text {root }}}
$$

Where $\mathrm{K}_{\mathrm{t}}$ is the stress concentration factor for the periodic notch embodied by the thread. This is treated as a

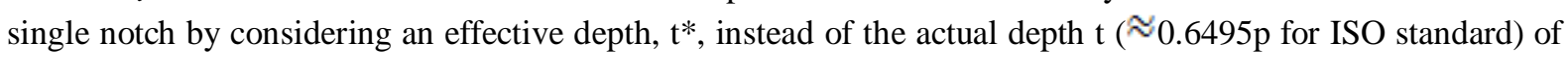
the thread profile using $t^{*}=\gamma \mathrm{t}$, where $\gamma$ is the correction factor and is calculated as follows [20]:

$$
\gamma=\frac{1}{\left(1+2.5^{t} / p\right)^{2}}
$$

The bending stress $\sigma_{x}$ can be calculated using Heywood's method [21] which is based on the load distribution given by Eq. (2.1). According to this method $\sigma_{x}$ is obtained using.

$$
\sigma_{x}=\left[1+0.26\left(\frac{e}{r}\right) 0.7\right] X\left[1.5 \frac{s}{e^{2}}+\left(1-\frac{\sin \delta}{4}\right) \sqrt{\frac{0.36}{b e}}\right] W
$$

Where

$$
w=\frac{w_{\max }}{\cos \delta}, \delta=\beta-\varphi
$$

For ISO thread,

$$
\begin{aligned}
& \mathrm{e} \cong 0.4278 \mathrm{p}, \mathrm{r} \cong 0.1443 p, \mathrm{~b} \cong 0.3847 p \\
& \mathrm{~s} \cong \cos \delta(0.3235-0.21875 \tan \delta) p
\end{aligned}
$$

The overall stress is obtained from a combination of $\sigma_{x}$ and $\sigma_{y}$. This must be done with care, since the two stresses do not occur at the same point. One of the appropriate combinations of these two stresses has been given by Heywood [22]

$$
\sigma_{t}=\sigma_{y}+\frac{\sigma_{x}}{1+m \frac{\sigma_{y}}{\sigma_{x}}}
$$

Where $m=[(60-\beta) / 44]^{2}$.

The fatigue life, or endurance, of a material refers to the number of repeated cycles of loading $(\mathrm{N})$ that a material will undergo before it fails. $\mathrm{N}$ will depend on the particular set of loading conditions. However, the general rule of thumb is that the higher the fatigue stress levels, the few number of loading cycles are required to cause failure. In most well designed bolted joints, however, fatigue failure will occur under high cycle loading. Fatigue data is most commonly presented in terms of S-N curves (maximum stress versus the number 
of cycles), as shown in "Fig.1" The material undergoes a definite fatigue limit. That is, it may withstand infinite cycles of loading without failing, as long as the applied stress is less than the fatigue limit. Although S-N curves are often produced based on tension loading

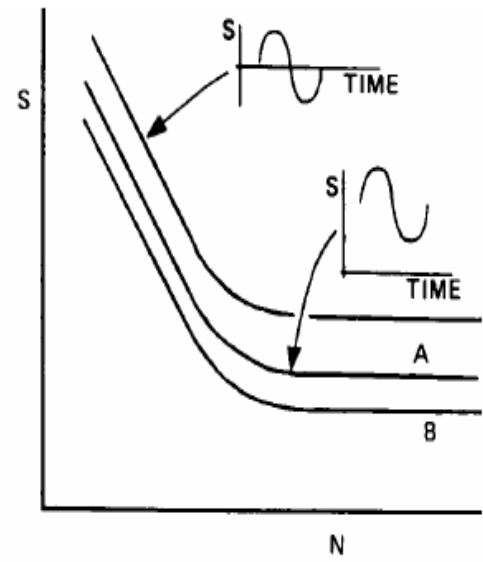

Fig.1:S-N Curve for varying magnitude of life altering stresses. Source[1]

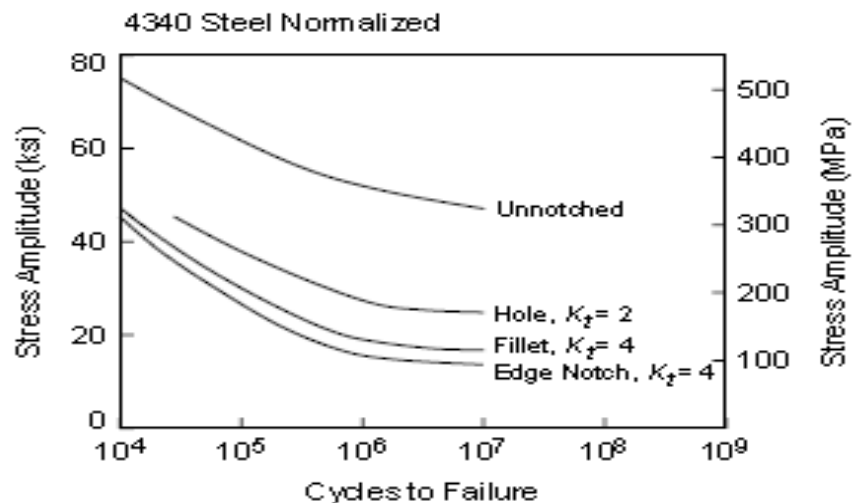

Fig.2: Effect of geometrical stress concentration on fatigue Source [23]

Along the axis of the fastener, it is important to recognize that if the fastener is subjected to some other form of stress as well as tension, its fatigue life will be adversely affected. Shear stress for example, would make it more susceptible to fatigue. There are many factors that will affect the fatigue life, each resulting in a different S-N curve. The major factors in order of importance that affect fatigue life are:

1. Shape of the connection.

2. Magnitude of stress excursions or variations.

3. Mean stress level.

4. Choice of material.

In most structures, fatigue cracking usually initiates at a stress concentration. The stress concentration may by inherent in the design, such as a fillet, hole, thread, or other geometrical feature, or the stress concentration can result from a manufacturing process, such as a rough surface finish or residual tensile stresses introduced by heat treatment. The effect of geometrical stress concentrations on fatigue is often studied by testing notched specimens. When a notch is present in a specimen under uniaxial loading, three effects are present: (1) there is an increase in concentration of stress at the root of the notch, (2) there is a stress gradient from the notch toward the centre of the specimen, and (3) a triaxial state of stress exists. The dramatic reduction in fatigue life of normalized 4340 steel sheet containing different types of stress concentrations is shown in "Fig.2" The effect of notches on fatigue strength is determined by comparing the S-N curves of notched and unnotched specimens. The data for the notched specimens are usually plotted in terms of nominal stress based on the net cross section of the specimen. The effect of the notch in decreasing the fatigue strength is reported as the fatigue strength reduction factor, or the fatigue notch factor, $K_{f}$;

$$
k_{f}=\text { fatigue limit unnotched } / \text { fatigue limit notched }
$$

For metals that do not have a definite fatigue limit, the fatigue notch factor is based on the fatigue strength at a specified number of cycles. Values of the fatigue notch factor vary with the severity of the notch, the type of notch, the material, the type of loading, and the applied stress level. Notched fatigue data are also reported using a notch sensitivity factor, q:

$$
q=(k f-1) /(k t-1)
$$


This relationship compares the theoretical stress-concentration factor, $K_{t}$, to the fatigue notch factor, $K_{f}$. In this relationship, a material that experiences no reduction in fatigue due to a notch will have a notch sensitivity factor of $q=0$, while one that experiences a reduction in fatigue up to the full theoretical value will have a notch sensitivity factor of $\mathrm{q}=1$. The value of $\mathrm{q}$ is dependent on the material and the Radius of the notch root, as illustrated by the plots shown"Fig.2" in for steels.

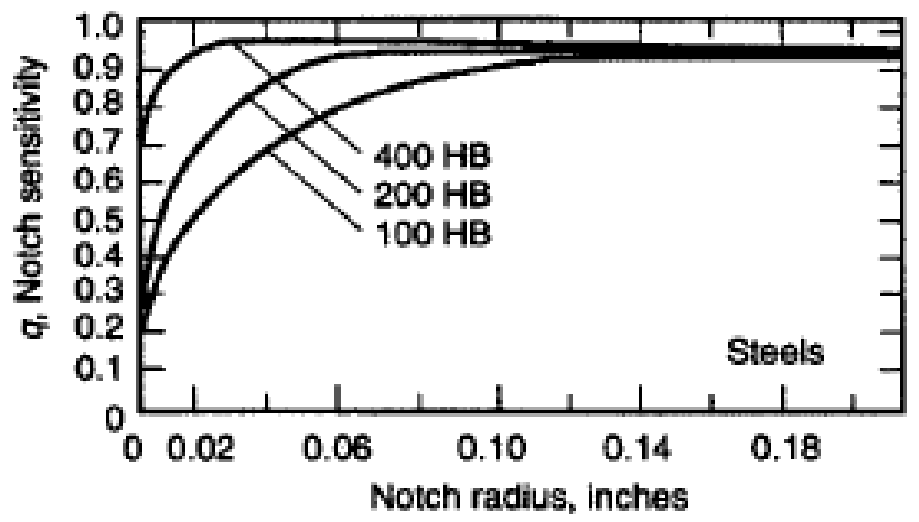

Fig.3: Notch Sensitivity verses notch radius for steels. Source [24]

The notch sensitivity factor, q, significantly decreases with smaller notch radii. Although this seems counterintuitive, it occurs because $K_{f}$ increases more slowly than $K_{t}$ with decreasing notch radius .For notches with large radii, $K_{f}$ is almost equal to $K_{t}$ for materials with small notches, $K_{f}$ is less than $K_{t}$. In addition, lowerstrength metals are less affected than high-strength metals by geometric discontinuities that reduce the fatigue resistance, because high-strength metals have a limited capacity for deformation and crack tip blunting. Because almost all fatigue failures start on a surface, the surface finish and Residual-stress state near the surface can have a profound effect on the fatigue strength. Since the early days of fatigue investigations, it was recognized that the fatigue life of a component is very dependent on the surface finish produced by machining or grinding operations, highly polished steel specimens perform much better in fatigue than even carefully machined surfaces. Further degradation in fatigue strength occurs for hot rolled and forged surfaces. Finally, when corrosion is introduced, the fatigue life can be seriously degraded. Parts that are formed at room temperature will contain residual stresses. For example, the surface of a part that was formed in tension will contain residual compressive stresses, and a surface that was in compression during forming will contain residual tensile stresses. Since fatigue always occurs under tensile loading, the surface with the residual tensile stresses will be the most prone to fatigue cracking. Similar to forming, some quenching operations during heat treatment can result in a tensile residual-stress pattern on the surface that will adversely affect fatigue strength.

According to Gane [19] a cursory examination of the mean stress values for the different thread geometries shows that the results appear to fall into two sets, those with a flank angle of $60^{\circ}$ or less (low strength) and those with angles of $90^{\circ}$ or over (high strength). There is no obvious consistent variation with either pitches or root diameter. This is confirmed by plotting the results. "Fig.4" shows the effect of flank angle on test specimens with constant thread pitch and root radius Although the scatter of results is large, a significant increase in strength clearly occurs between $60^{\circ}$ and $90^{\circ}$,the effect of thread pitch is less clear.

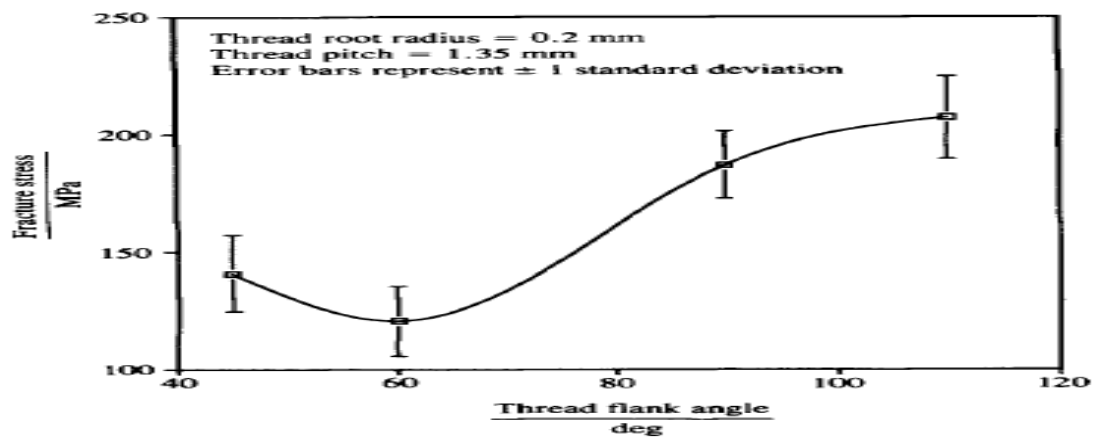

www.iosrjournals.org 
Fig.4: Effect of thread flank angle on fatigue stress. Source [19]

\section{II: Experimental Work}

The standard specimen with five different thread profiles means changing flank angles $\left[47^{\circ}, 55^{\circ}, 60^{\circ}\right.$, $90^{\circ}$, and $110^{\circ}$ ] with a similar pitch of $1.5 \mathrm{~mm}$ having major diameter of $10 \mathrm{~mm}$ and minor diameter of $8.38 \mathrm{~mm}$ with coarse threads has been used for this work.

The mechanical properties of the bolt material (mild steel) were obtained from a number of tensile tests. These properties were then used to select the appropriate amplitude of the reversed loading in fatigue tests. These properties are the following:

- Yield strength, $\sigma_{y p}=170 \mathrm{MPa}$, ultimate tensile strength, $\sigma_{u l t}=265 \mathrm{MPa}$; Young's modulus $\mathrm{E}=$ $207 \mathrm{MPa}$, and Poisson's ratio $v=0.3$.

The design of the standard specimen has been according to the following:

- The ends of the specimen were made of the form to suit the type of machine used and the material being tested.

- The grip ends of the specimens were made symmetrical about the axis of reduced test section.

- The forms of the test specimens rectangular or circular cross sections depends upon the nature of particulars required from the tests and naturally the form in which the material is available. Where fundamental fatigue properties are desired, circular cross sections are recommended.

\subsection{Specimen Geometry, Testing Apparatus And Procedure}

All the test specimens employed for a fatigue determination shall have the same nominal dimensions as follows, shown in. "Fig.5" Total length------150mm, Major diameter-------10mm, Minor diameter (threaded portion) ---------8.38mm, Threaded portion length ------------50mm

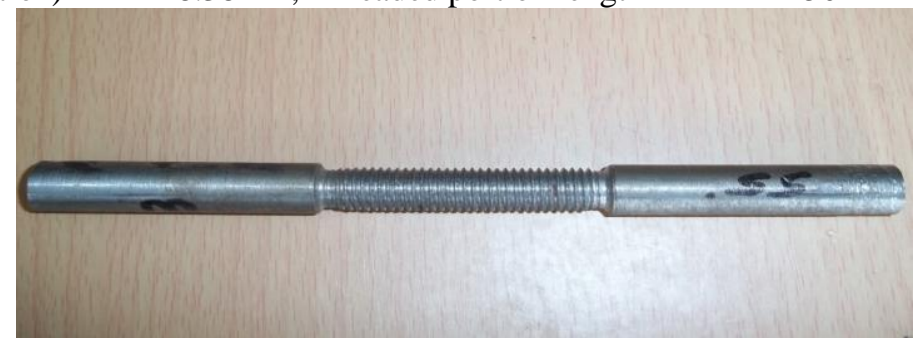

Fig.4: Testing Specimen

Fatigue tests were conducted using R.R Moore fatigue testing machine. The tests were performed under the sinusoidal cyclic loading. A general view of the testing machine each load has been obtained by the product of the designated stress and the root area of the bolt. The stresses were selected between the ultimate strength of the bolt material, $\sigma_{u l t}{ }^{z}$ and $0.4 \sigma_{e}$. The endurance limit of the bolt material $\sigma_{e}$ has been obtained from the S-N curve of the bolt material and was found to be 160MPa for mild steel bolts. The load obtained in this way was considered as the amplitude of a sinusoidal load applied to the specimen by the testing machine. The load fluctuated between 0 and $\sigma_{\max }, i, e \quad R=\sigma_{\min } / \sigma_{\max }=0$. The number of cycles corresponding to the failure has been recorded as the fatigue life of the bolt under testing. The core stresses were calculated as $\sigma_{\text {core }}=P / A_{\text {core }}$. These stresses were then used to compare the fatigue life of threaded bolts of different flank angles. The "Fig" below shows the fatigue failed sample

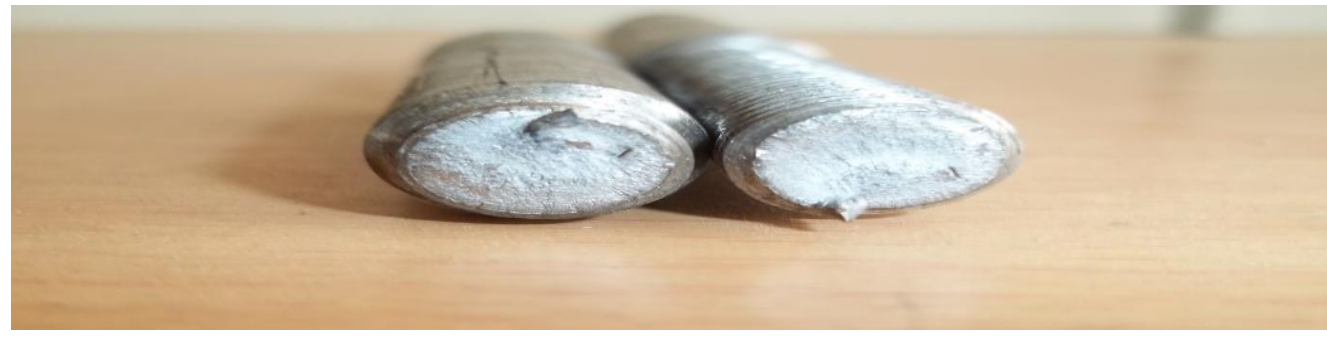

\section{III: Experimental Data And Results}


The experimental results are given in Tableland in the same way data has been manipulated for all the samples. The table shows the fatigue life of threaded specimens with different flank angles at different core stresses. The tests were performed on each profile with six samples i.e. total numbers of thirty experiments were performed on five profiles respectively, and it must be mentioned that all experimental data, have been used to draw all S-N curves shown in the results

\begin{tabular}{|c|c|c|c|}
\hline SAMPLE & $\begin{array}{c}\text { FLANK } \\
\text { ANGLE } \\
\text { (DEGREE) }\end{array}$ & $\begin{array}{c}\text { APPLIED } \\
\text { CORE } \\
\text { STRESS } \\
\text { (MPa) }\end{array}$ & $\begin{array}{c}\text { FATIGUE } \\
\text { LIFE } \\
\text { CYCLES }\end{array}$ \\
\hline I & 47 & 106.67 & 584646 \\
\hline II & do & 142.23 & 209426 \\
\hline III & do & 177.79 & 104784 \\
\hline IV & do & 213.35 & 54346 \\
\hline V & do & 248.91 & 34711 \\
\hline VI & do & 284.47 & 10320 \\
\hline
\end{tabular}

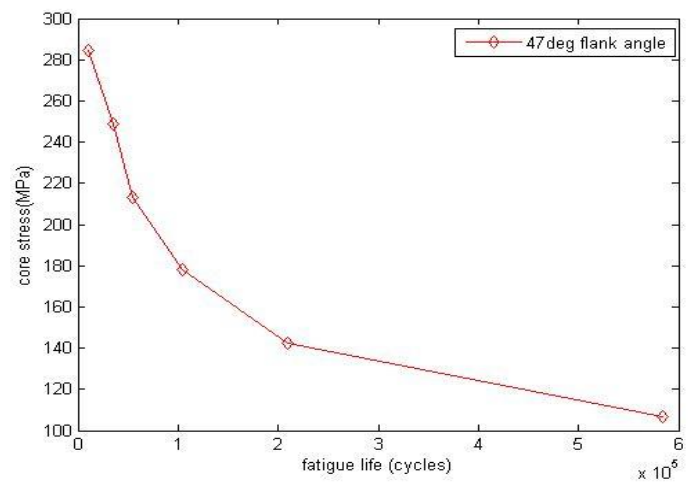

Table1

\section{Graph 1}
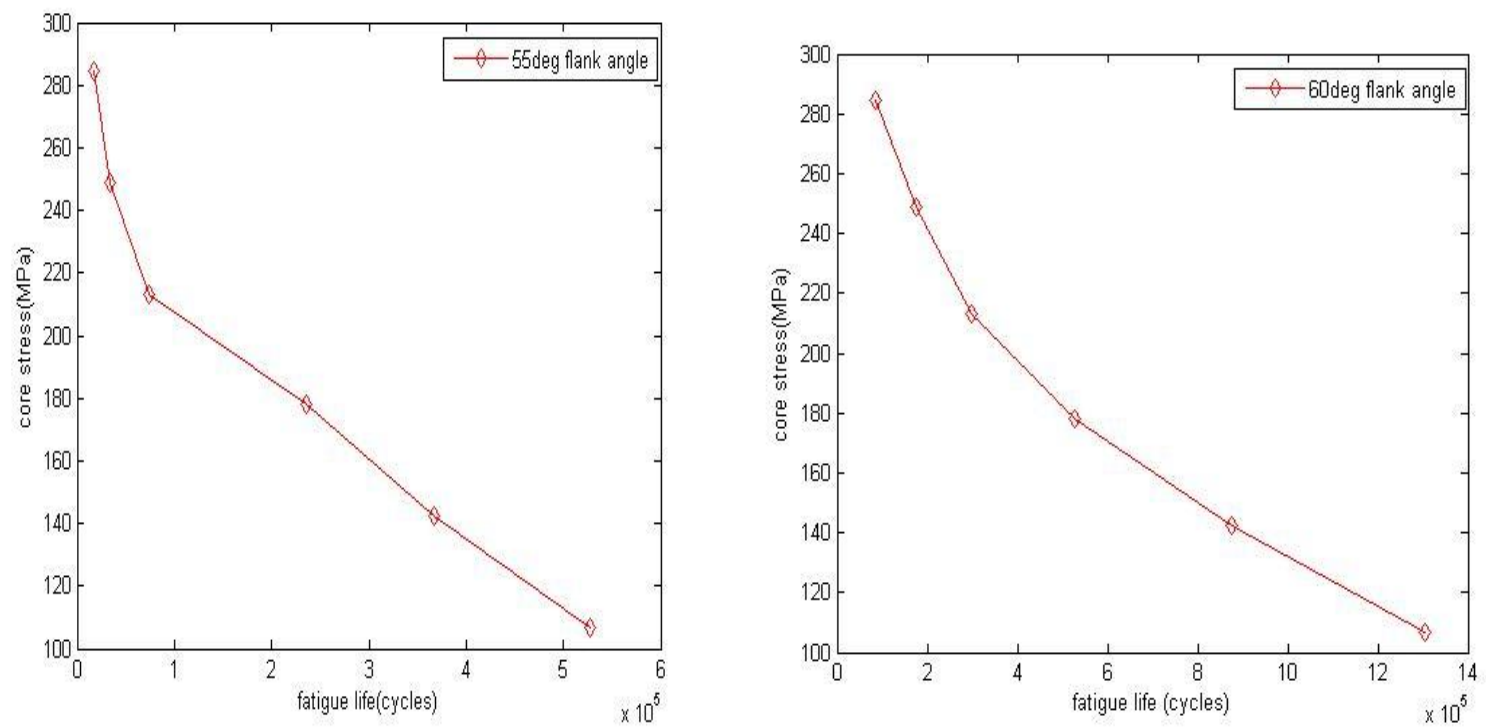

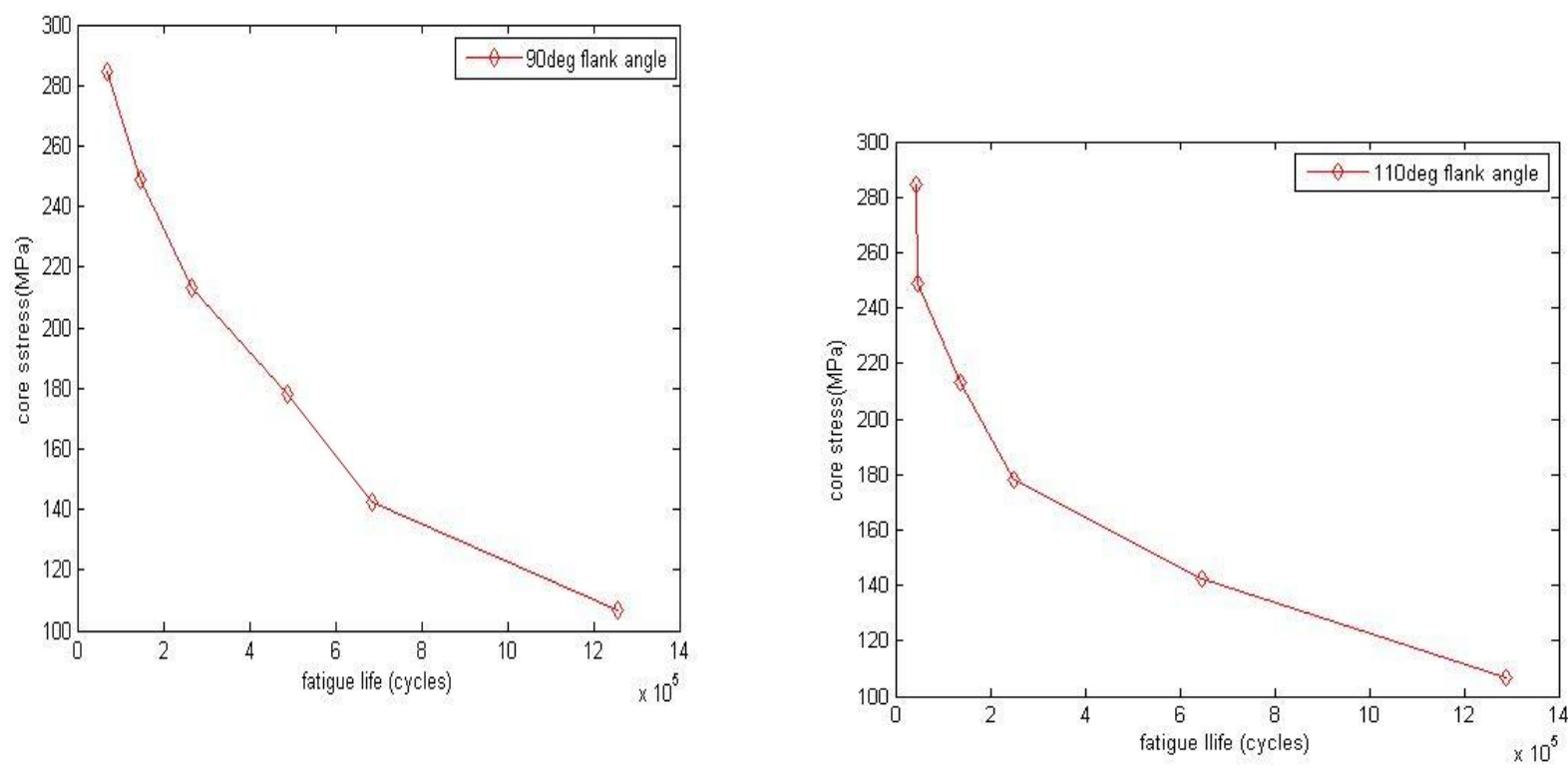

\section{Conclusion}

The fatigue strength of threaded connections with various thread geometries, made from mild steel material has been measured. The core stress of different thread profiles with various flank angles varies between 106.67 and $284.47 \mathrm{MPa}$, and the results obtained by plotting the S-N Curves of various thread flank angles has been compared with the work of Gane [19] , the results obtained agreed well with his work. From the results obtained following conclusions can be derived:

The fatigue strength of bolts appear to fall into two sets, those with a flank angle of $55^{\circ}$ or less ( low strength ) and those with angles of $60^{\circ}$ or over ( high strength ) under the constant pitch and applied core stress.

From the S-N Curve of $60^{\circ}$ flank angle specimens have approximately $10-20 \%$ higher fatigue life when compared with the S-N Curve of $90^{\circ}$ flank angle specimens.

\section{Refrences}

[1] R.A. Higgins, "Engineering Metallurgy_Applied Physical Metallurgy" 6th ed., Arnold, 1993

[2] Bouwman, L.P., "Bolted connections dynamically loaded in tension” ASCE, J. of the Structural Division, Vol. 108, September 1982. Arnold SM. "Effects of screw threads on fatigue". Mech Eng 1943; vol. 65: 497-505.

[4] Patterson EA. "A comparative study of methods for estimating bolt fatigue limits". Fatigue Fract Eng Mater Struct 1990; vol.13:5981.

[5] Burguete RL, Patterson EA. "The effect of mean stress on the fatigue limit of high tensile bolts". Proc Inst Mech Engrs 1995; vol. 209: 257-62.

[6] Shigley JE, Mischke CR. "Mechanical engineering design". $5^{\text {th }}$ edition. New York: McGraw-Hill, 1989.

[7] Cook NH.” Mechanics and materials for design”. New York: McGraw-Hill, 1985.

[8] Gunn K. "Effect of yielding on the fatigue properties of test pieces containing stress concentrations". Aeronaut Quart 1955; vol. 6: 277-94.

[9] Waltermire WG. "Coarse or fine threads" Mach Des 1960; vol. 32(6):134-40.

[10] Dragoni E. "Effect of thread pitch and frictional coefficient on the stress concentration in metric nut-bolt connections". ASME Trans J Offshore Mech Arctic Eng 1994; vol. 116(1): 21-7.

[11] Yokushev AI. "Effect of manufacturing technology and basic threaded connections." Oxford: Pergamon; 1964.

[12] Kloos KH, Thomala W. "Fatigue strength of threaded connections" Part 4: "effect of decaburization and thread pitch" 1974; vol. 11(5):22-9.

[13] Maduschka L. "Stresses in threaded connections and shape optimization" 1936; vol. 7(6):229-305.

[14] Birger IA. "Load distribution in screw threads" (in Russian).1944; vol. 11(1):7-12.

[15] Kenny B, Patterson EA. "The distribution of load and stress in the threads of fasteners a review". 1989; vol.2:87-105.

[16] Patterson EA, Kenny BA. "Modification to the theory for the load distribution in conventional nuts and bolts".1986; 21(1):17-23.

[17] Sopwith DG. "The distribution of load in screw threads". Proc IMechE 1984; 159: 337, 383, 391, 398.

[18] Stoeckly EE, Macke HJ. "Effect of tapper on screw thread load distribution”. ASME Trans 1952; 74(1):103-12.

[19] N Gane and F Polivka, "Effect of thread form on the strength of ceramic bolts". Journal of mechanical engineering science, vol 209, IMechE 1995.

[20] Dragoni E.” Stress concentration in periodic notches”. Proceeding of XXIII AIAS National Congress, Rende, 1994. p. $441-7$.

[21] Heywood RB. "Tensile fillet stresses in loaded projections". Proc IMechE 1984; 159: 384-91.

[22] Heywood RB. "Designing by photoelasticity". Chapman and Hall: London; 1952

[23] J. Collins and S. Daniewicz, "Failure Considerations", Mechanical Engineers Handbook, John Wiley \& Sons, Inc., 1998 
[24] M.R. Mitchell, Fundamentals of Modern Fatigue Analysis for Design, Fatigue and Fracture, Vol 19, ASM Handbook, ASM International, 1996

[25] Bouwman, L.P., Gresnigt, A.M. and Dubois, G.A., "European Recommendations for Bolted Connections with Injection Bolts," ECCS-TC10 draft.

[26] M.A. Meyers and K.K. Chawla," Mechanical Metallurgy_Principles and Applications”, Prentice-Hall Inc., 1984

[27] Bouwman, L.P.," Bolted connections dynamically loaded in tension”, ASCE, J. of the Structural Division, Vol. 108, No. ST, September 1982.

[28] Euro code 3: "Design of steel structures": ENV 1993-1-1: Part 1.1, General rules and rules for buildings, CEN, 1992

[29] Frost, N.E., March, K.J., Pook, L.P., "Metal fatigue”, Oxford University Press 1974

[30] G. H. Majzoobi, G. H. Farrahi, N. Habibi. , "Experimental evaluation of the effect of thread pitch on the fatigue life of bolts", International journal of Fatigue vol. 27(2005) 189-196. 